\title{
List of abbreviations
}

$\mathrm{AD}$

AE

AEER

APJED

ASCN

B.A.

BC

$\mathrm{BSPh}$

CAPI

CAS

$\mathrm{CB}$

$\mathrm{CC}$

CED

$\mathrm{CP}$

CPG

CPSU

CRRC

CUNY

d.

DAAD

DVV

EAS

EB

ENRS

ed.

EF

EU

EUP

f.

IDFI

IDP

IJSL

IRI

JEMIE

JGO

anno domini

American Ethnologist

Anthropology of East Europe Review

Asia Pacific Journal of Educational Development

Academic Swiss Caucasus Network

Bachelor of Arts

before Christ

Bulletin de la Société Française de Philosophie

computer-assisted personal interviewing

Central Asian Survey

Caucasus Barometer

Central Committee

Caucasus Educational District

Communist Party

Communist Party of Georgia

Communist Party of the Soviet Union

Caucasus Research Resource Center

City University of New York

delo (file)

Deutscher Akademischer Austauschdienst (German Academic Exchange Service)

Deutscher Volkshochschul-Verband (German Adult Education Association)

Europe-Asia Studies

Eurobarometer

European Network of Remembrance and Solidarity

editor

Europe Foundation

European Union

European Union Politics

fond

Institute for the Development of Freedom of Information

internally displaced person

International Journal of the Sociology of Language

International Republican Institute

Journal on Ethnopolitics and Minority Issues in Europe

Jahrbücher für Geschichte Osteuropas 


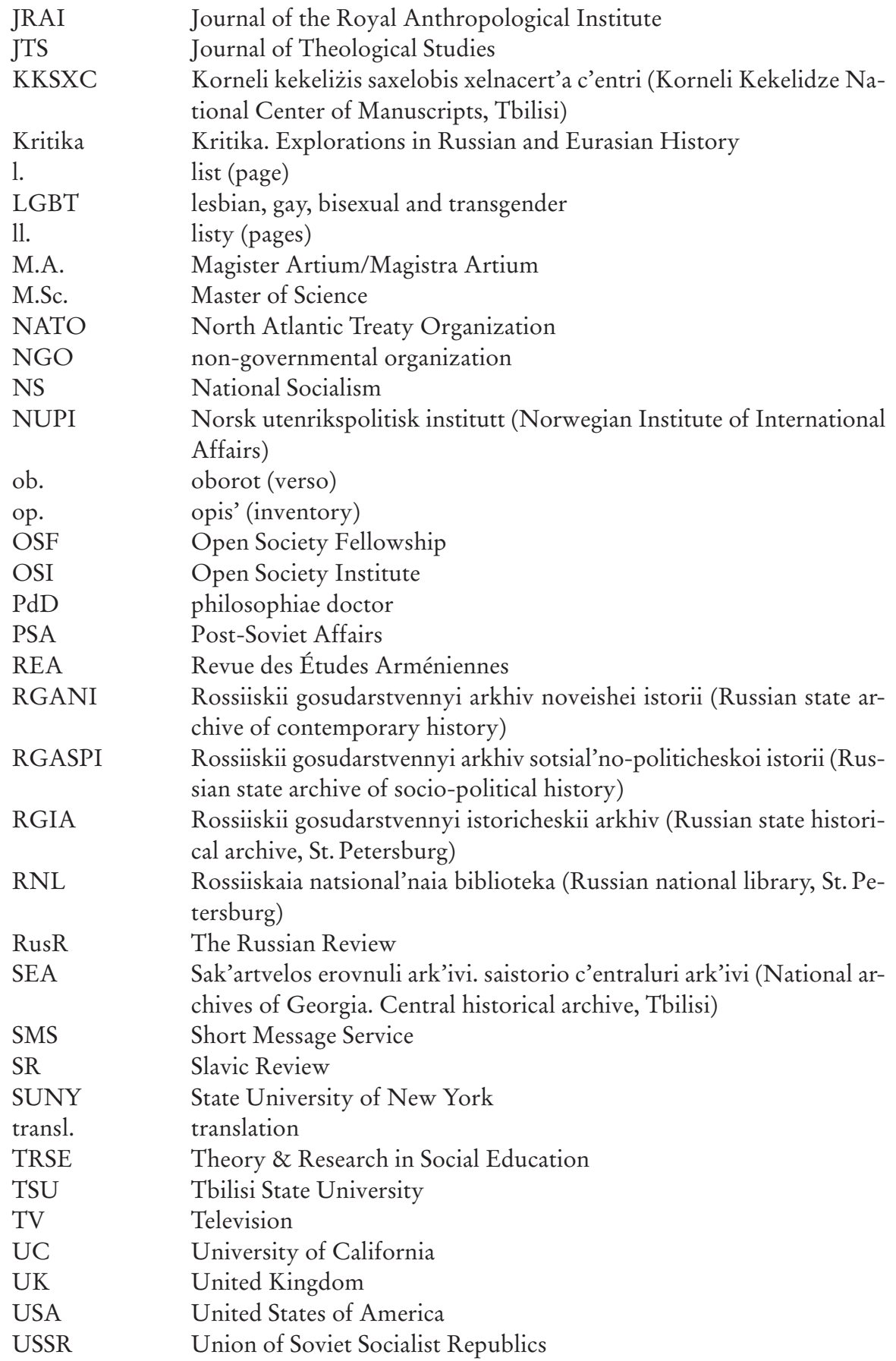

